\title{
IMPACT PRESSURE ON MECHANICAL PROPERTIES OF ALUMINUM BASED COMPOSITE BY ECAP-PARALLEL CHANNEL
}

\author{
${ }^{1}$ Agus PRAMONO, ${ }^{2}$ Klodian DHOSKA ${ }^{*},{ }^{3}$ Irida MARKJA \\ ${ }^{4}$ Lembit KOMMEL \\ ${ }^{1}$ Faculty of Engineering, University of Sultan Ageng Tirtayasa. Jl. Jend Sudirman km. 3 \\ Cilegon Banten 42435 Indonesia, e-mail: agus.pramono@untirta.ac.id \\ ${ }^{2}$ Faculty of Mechanical Engineering, Polytechnic University of Tirana, Mother Teresa No.4 \\ 1001 Tirana, Albania, e-mail: ${ }^{2}$ kdhoska@upt.al, ${ }^{3}$ imarkja@fim.edu.al \\ ${ }^{4}$ Faculty of Material Engineering, Tallinn University of Technology, Ehitajate tee 5, 19086 \\ Tallinn Estonia, e-mail: ${ }^{4}$ lembit.kommel@ttu.ee
}

Received 12 April 2018; accepted 31 October 2018

\begin{abstract}
The pressing of equal channel angular pressing - parallel channel process has an effect on microstructure and mechanical properties of the composite materials. Finite element has been used for conducting pressure effect through parallel channel for knowing distribution effect pressing. The materials AA1070 and AA6061 powder matrix composite with $\mathrm{Al}_{2} \mathrm{O}_{3}$ nano fiber were used as reinforcement. Mechanical properties and scanning electron microscope were observed in room temperature pressure and in case where the temperatures were higher than recrystallization value. Both results were compared to determine the effectiveness of pressure on each process. The characterization of aluminum composites on the aspects and phenomena of the distribution of pressing effect on hot and cold conditions treasured by finite elements will be explained in this paper.
\end{abstract}

Keywords: Equal channel angular pressing - parallel channel, Aluminum based composite, Hot/cold pressing and finite element model simulation

\section{Introduction}

During the last decade, Equal Channel Angular Pressing (ECAP) has emerged as a widely known procedure for the fabrication of ultrafine grained metals and alloys. ECAP are the pressing process between compression and tensile forces that happened in angular die [1], [2]. Application of pressure in ECAP processes has been used in shear stress and simple shear of monotonic load to cyclic loading and cross the mold [3], [4]. An advantage of ECAP compared to conventional metal working processes, like forging

\footnotetext{
${ }^{*}$ Corresponding Author
} 
or extrusion, is the ability to achieve a high strain without dimensional changes of samples [5].

ECAP technology is generally applied to solid objects like the form of bars or cylinders but also ECAP can be applied for consolidation of powder. Important differences of pressing powders were cracks that evolve more easily on the surface. In order to avoid cracking during consolidation, powder has been putted in a tight outer jacket, as shown in Fig. 1a. ECAP for powder form have been produced flawless materials, normally by use of heating during pressing. This means that compaction of alloy powders is possible by wrapping the powder and heating the die [5]-[7]. ECAP method can produce a fine grain structure and combined with oxide inclusions from particle surfaces yielding in high strength.

In the principle, the existence of ECAP was replaced for conventional processes due to production of a superfine structure by using conventional metal working methods [1], [2]. Forming metal of traditional process like forging, extrusion, rolling and drawing can impose significant limitations on required equipment and product characteristics like sizes were restricted. Furthermore, changes occur in work piece dimensions with higher levels of non-uniformity strain in product [8]. These limitations can be overcome by Severe Plastic Deformation (SPD).

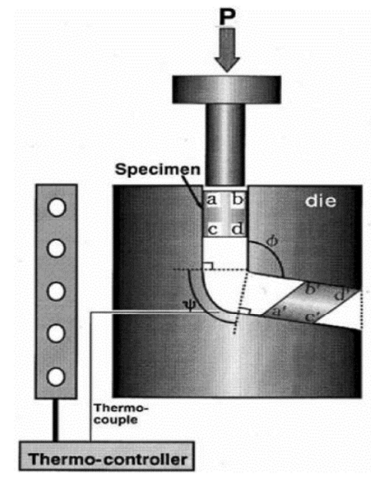

a)

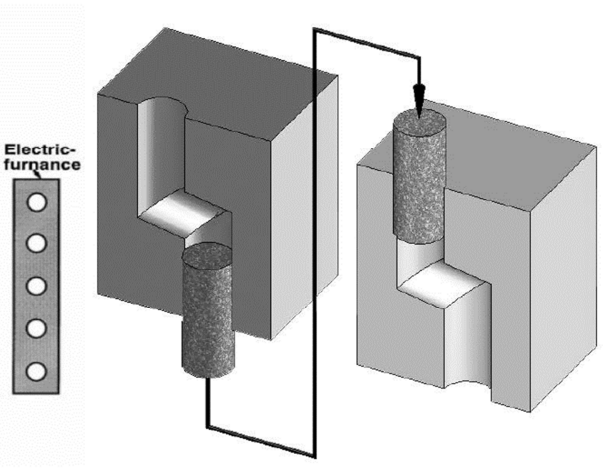

b)

Fig. 1. Scheme of ECAP Consolidation: a) the powder form is inserted into a capsule copper by labeled in jacket wrap a-b-c-d [6], b) Route of parallel channel 2 passed [9]

ECAP is one kind of SPD processes by combining pressing and tensile stress in the mold. ECAP is manufacturing process for the metal that has ability for introducing significant grains refinement into large bulk samples. Typically, it reduces the grain size into the sub-micrometer level (achieved size $<1 \mu \mathrm{m}$ ), and this produce a material that is capable for providing the unusual nature of the material [8], [9]. In the practices conventional ECAP can be produced a single abrupt angle billets with gross distortions at both ends. It has a high cost process because it leads to wastage of the materials around $30 \%-50 \%$ [10]. The alternative procedure was developed by Valiev et al [6], [9], in which ECAP has been conducted by using two parallel channels (ECAP-PC) 
further developed with parallel lines on pure materials, alloys and composite materials [6].

The principle work of ECAP-PC is the application of simple forces consecutively in two bend of deformation zones on the dies, which correspond at two consecutively arranged zones of intersecting channels in the tools. ECAP-PC is a relatively new modification procedure from conventional ECAP. In comparison to the traditional ECAP, the main advantages of ECAP-PC were related to the higher efficiency, lower wastage of material, lower cost on processes, which has made this method more attractive for industrial applications [11], [12]. Measurement effects of the heat/cold pressing on parallel channel - ECAP process play an important role to obtain the stress distribution and strain values in several positions. Based on it, this paper will be focused on the characterization of aluminum composites in the aspects and phenomena of the distribution of pressing effect on hot and cold conditions treasured by finite elements [13], [14].

\section{Materials and experimental methods}

Pure aluminum and aluminum alloy with average particle size \pm 75 till $100 \mu \mathrm{m}$ was received from Aluminum Powder Company Ltd (ALPOCO). $\mathrm{Al}_{2} \mathrm{O}_{3}$ Nano Fibers (ANF) had particle size in the range of $7 \mathrm{~nm}$. It has mixture by mechanically activated of ball milling. The ration volume fractions were $97.3 \%$. Composite was milling by ball milling process on $60 \mathrm{rpm}$ for 24 hour. The temperature used in furnace was $400{ }^{\circ} \mathrm{C}$ and held for one hour. Characteristic of the ECAP-PC during the processing of a pass has been focused in two different events shearing occurs and have been slide it in two subsequent deformation zones in accordance with the following two junction channels in die-sets as can be seen in Fig. 2.

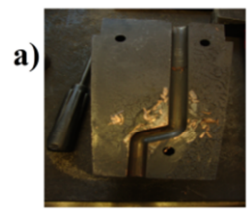

c)

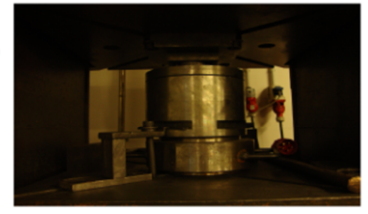

b)

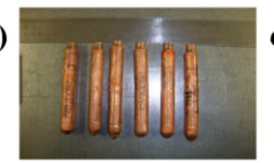

d)

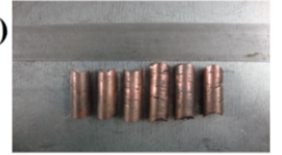

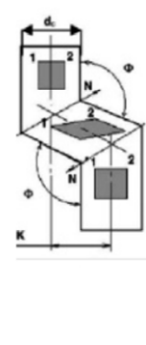

e)

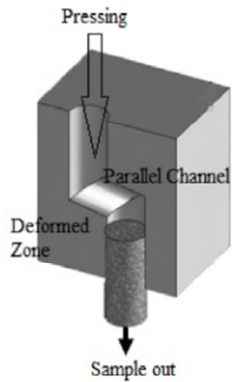

Fig. 2. Stage of ECAP- parallel channel process: a) ECAP-PC dies; b) Copper tube to wrap composite material c) Place dies in hydraulic press machine

The value of the displacement between the two channels, deformed zone, and the corner of the intersection of two channels were the main parameters of die geometry, which affects the pattern of flow and strain-stress state parallel channel ECAP process. The samples were transported to the non-heated ECAP-PC for 5 to 10 seconds and 
pressed at the rate of 4 till $12 \mathrm{~mm} / \mathrm{s}$ through the single pass. The pressure for compacting was in the range of 400 till $500 \mathrm{MPa}$. Vickers Hardness (HV10) and quasistatic compressive strength test were measured on cylindrical specimens with diameter of $1.5 \times 12 \mathrm{~mm}$. Scanning Electron Microscope (SEM) TM-100 Hitachi was applied to determine the grain morphology and phase distribution. Finite element was used for quantitative temperatures and stress - strain analysis.

\section{Results and discussions}

Microstructure and mechanical testing of the composite has been used to observe the characteristics and changes of the morphology structure of composite materials. The finite element was used to track the impact of temperature on defects like cracks or process failures and to know the stress strain distribution occurring in the sample. Based on it, the phenomenon of change of the mechanical properties and microstructural behavior has been analyzed.

\subsection{Microstructure analysis}

The microstructure and grain morphology was observed. There are some microcracks in matrix phase during cold temperature process as it can be seen in Fig. 3. In room temperatures the pressing have not form in a bond on composite of microstructures, thus the interphase boundary of aluminum as matrix grains neck and reinforced were not formed.

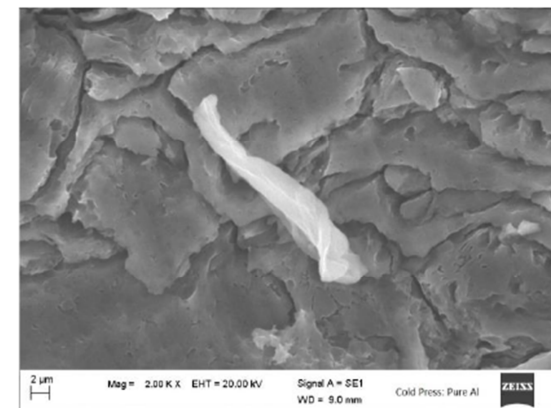

a)

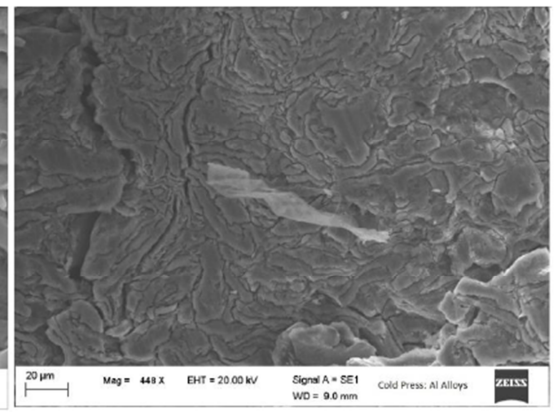

b)

Fig. 3. Results of ECAP-PC, a) Pure aluminum composites by room pressing; b) Aluminum alloys composites by room pressing

In hot temperatures the pressing process has made the formation of the neck grain more easily and more uniform (see Fig. 4).

Aluminum alloys have deposits of dispersive where the $\mathrm{Mg}_{2} \mathrm{Si}$ as precipitation particles were not well dispersed. The hot pressing of the ECAP-PC process helps the formation of aluminum powder grains bond with reinforcement. In hot conditions, the 
working temperature forms a neck bond between the matrix and reinforcement, so that no cracked and the like occur, otherwise under conditions of room

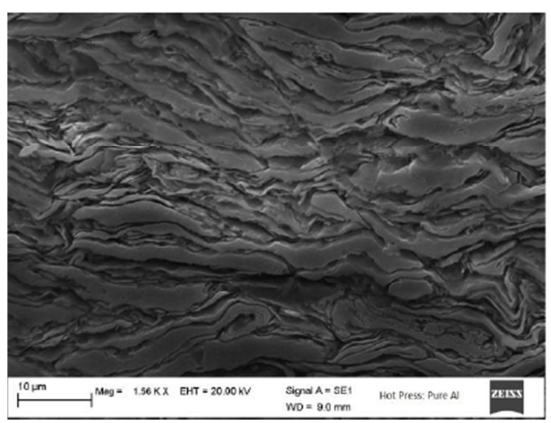

a)

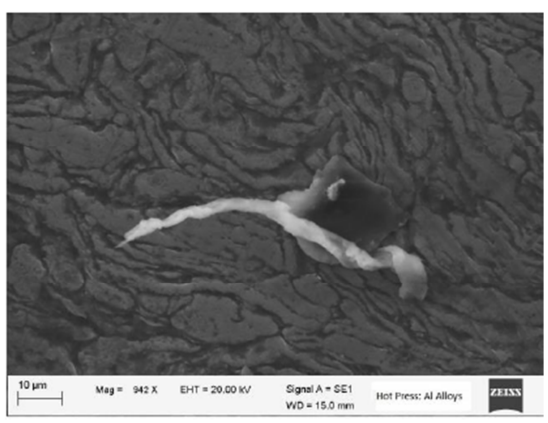

b)

Fig. 4. Results of ECAP-PC, a) Pure aluminum composites by hot pressing, b) Aluminum alloys composites by hot pressing

Many of the crack gaps were formed through pressing in room temperatures as a result of the non-bonding where $\mathrm{Al}_{2} \mathrm{O}_{3}$ Nano fibers have been attached to the grain boundaries as reinforcement. While on hot temperatures of pressing, especially pure aluminum bonds were formed very tightly. The results in a bond between the matrix and reinforcement have been quite good. In the other hand, Fig. $4 b$ depicts $\mathrm{Al}_{2} \mathrm{O}_{3}$ nano fibers unbound on pore of the hole. This is due to the compound alloys in the composite acting as a precipitation, so that at certain pressure limits, especially the lower pressure resulting in a lack of forces to form bonds. In case of the small pressures is not sufficient to give the effect of deformation load to close the pores that were formed between the matrixes with the reinforcement, so that there is alumina scattered out of the pore.

\subsection{Modeling of the distribution temperature and the pressure of the composite material}

During the Cold Pressing (CP) on composites materials insufficient consolidation has been appeared. Fig. $5 a$ depicts the ECAP-PC defects originate from cracking and fragmentation, which were considered as local mechanisms. The results has shown the friction contact of the difference in materials flow which consequently blocking adhesion and causing micro-cracks as the $\mathrm{Al} / \mathrm{Al}_{2} \mathrm{O}_{3}$ nano fibers powder were wrapped in $\mathrm{Cu}$. In Fig. $5 b$ modeled that blue indicates no heat flow, on the samples. Visible temperature only shows a value of 25 . Fig. $5 c$ depicts distribution of stress, which was not uniform. This phenomenon was caused from strain accumulation along the copper capsule and dies interphase which resulted in micro-cracks. Due to the cold temperature in the mold, the flow rate is also small. The average normal force flows were 1.932e 8 1929e8 Pascal, in accordance with the value issued by FEM-ANSYS R.14.5.

At Hot Pressing (HP), the flow of stress is more easily moved toward the center point but still not evenly distributed. Based on HP, micro-cracks do not occur as can be 
seen in Fig. $6 a$ where high densification was obtained. In Fig. $6 b$, heat flow moved from the upper to the lower end, the temperature that works based on the simulation of FEM ANSYS R.14.5 were moving from a temperature of $395-404{ }^{\circ} \mathrm{C}$ which has been resulted in stress and strains flow from the circle of the $\mathrm{Cu}$ capsule around the edges as it can be observed in Fig. $6 c$ and explains no micro-crack around grains. The normal stress acting on the heat tension is quite evenly distributed and is able to create a good bond between the matrices of reinforcement, the normal tension that flows fairly large, based on simulation of FEM-ANSYS R.14.5, the flow normal stress was 2,5029e8 5,1585e7 Pascal.

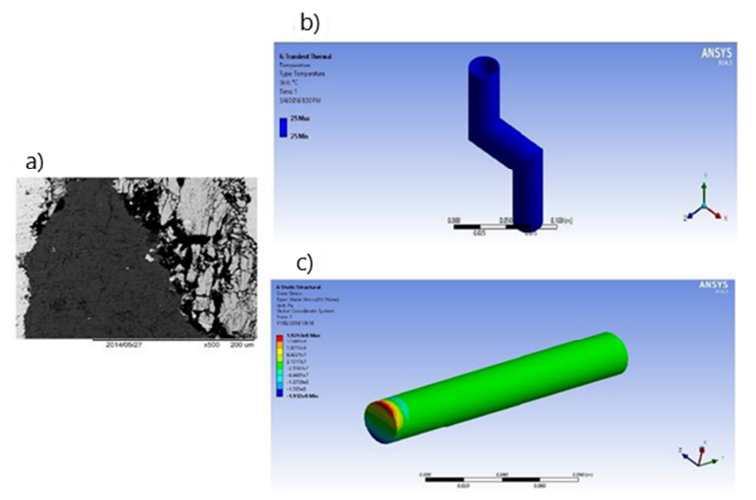

Fig. 5. FEM simulation: a) Microstructure after CP; b) effect of room temperature; c) effect of $\mathrm{CP}$

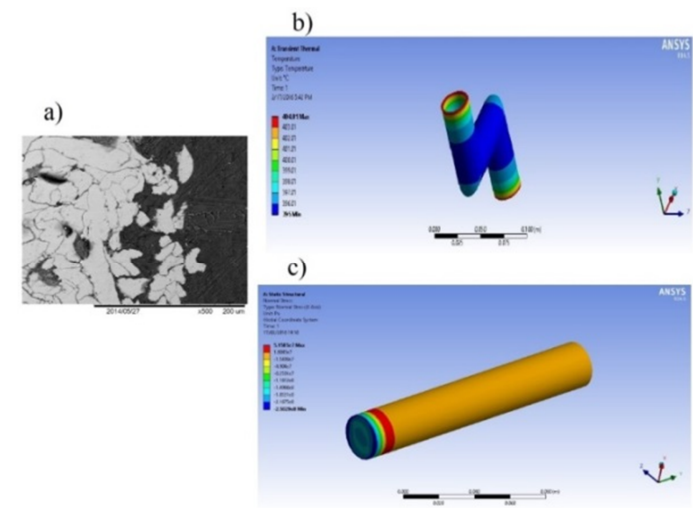

Fig. 6. FEM simulation: a) microstructure after HP; b) effect of hot temperatures; c) effect of HP

\subsection{Mechanical properties}

The results of the mechanical properties of aluminum based composite by ECAP-PC are shown in Fig. 7. The hardness value on pure aluminum of composite was 30.1 
HV10 and 73.6 HV10 on composite of alloys. In case of the hot pressing the value was $69.3 \mathrm{HV} 10$ for pure aluminum of composites and $94.5 \mathrm{HV} 10$ for aluminum of composite alloys. In pure aluminum the hardness was lower than aluminum of composite alloys. In compressive strength at room temperatures the pressing values were $124 \mathrm{MPa}$ with $3 \%$ elongation and alloys aluminum of composite were $73 \mathrm{MPa}$ with elongation of $2.4 \%$. Hot pressing of pure aluminum of compressive strength was $57 \mathrm{MPa}$ with $14.5 \%$ elongation and for aluminum of composite alloys was $95 \mathrm{MPa}$ with elongation $14 \%$.

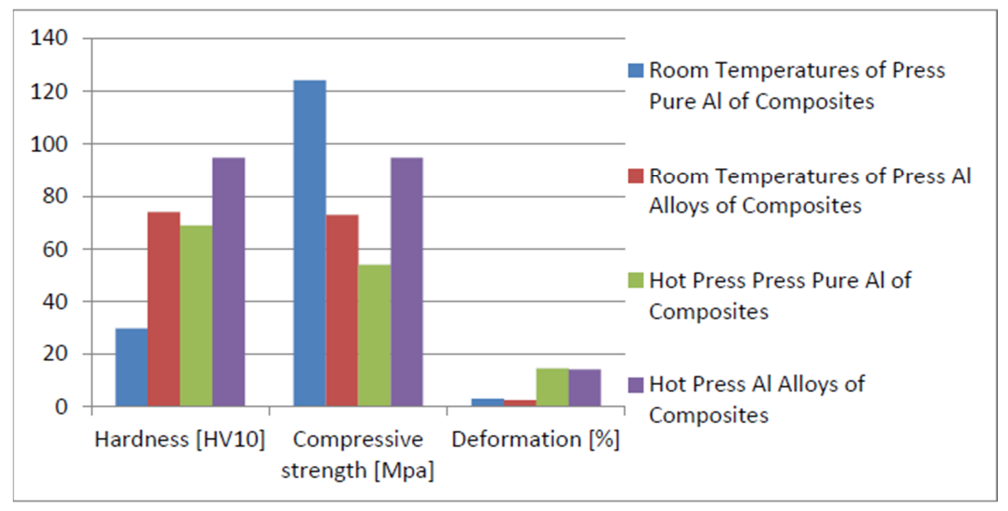

Fig. 7. Mechanical properties of aluminum based composite by ECAP-PC

From the analysis of finite element (ANSYS R.14.5) can be analyzed that the stress distribution is also influenced by hot temperature of pressing, at uniformly distributed stress-strain hot temperature, while at room temperature of pressing the stress distribution was not evenly distributed for producing cracks in microstructure. At room temperature $25{ }^{\circ} \mathrm{C}$, the voltage was relatively small and not well distributed. Based on the finite result the stress concentration was at the end of the sample and producing the cracks. The distribution of stress-strain generated at room temperature is $1929 \cdot 10^{8}$ $1932 \cdot 10^{8} \mathrm{~Pa}$, whereas in the hot pressing is generated $2502 \cdot 10^{8}-5158 \cdot 10^{8} \mathrm{~Pa}$ distributed of stress-strain on the sample.

\section{Conclusions}

ECAP-parallel channel technology has been used to refine conventional ECAP. Cold pressing of ECAP - PC has given a result in cracking of the microstructure due to their compression that was not evenly distributed. This was caused by the absence of heat temperature that transforms the heat energy of press into each part. Hot pressing provides sufficient heat energy to distribute the pressure where the heat was evenly distributed and these results in a more uniform microstructure than cold press. Cold pressing provides an excessive stretching in the hardening where the hardness will rise significantly by causing the cracks. The new results have shown that ECAP-PC can be used also for composite materials. The FEM-ANSYS R.14.5 was used to predict the 
temperatures that work and the value of the flow rate. In the cold press the heat does not flow well enough and the flow stress works abnormally. For hot press conditions, the operating temperature works well and the stress distribution was able to produce a strong bond between aluminum as a matrix of alumina as reinforcement.

\section{References}

[1] Pramono A., Kollo L., Kallip K., Veinthal R., Gomon J. K. Heat treatment of ultrafine grained high-strength aluminum alloy, Key Engineering Materials, Vol. 604, 2014, pp. 273-276.

[2] Pramono A., Kollo L., Kallip K., Veinthal R., Gomon J.K. Heat treatment of ultrafine grained AA6061 consolidation by equal channel angular pressing, Applied Mechanics and Materials, Vol. 771, 2015, pp. 252-256.

[3] Segal V. M. Severe plastic deformation: simple shear versus pure shear, Materials Science and Engineering: A, Vol. 338, No. 1-2, pp. 331-334.

[4] Rosochowski A. Processing metals by severe plastic deformation, Solid State Phenomena, Vol. 101-102, 2005, pp. 13-22.

[5] Azushima A., Kopp R., Korhonen A., Yang D. Y., Micari F., Lahoti G. D., Groche P., Yanagimoto J., Tsuji N., Rosochowski A., Yanagida A. Severe plastic deformation (SPD) processes for metals, CIRP Annals - Manufacturing Technology, Vol. 57, No. 2, 2008, pp. 716-735.

[6] Valiev R. Z., Langdon T. G. Principles of equal channel angular pressing as a processing tool for grain refinement, Progress in Materials Science, Vol. 51, No. 7, 2006, pp. 881-981.

[7] Valiev R. Z., Islamgaliev R. K., Alexandrov I. V. Bulk nanostructured materials from severe plastic deformation, Progress in Materials Science, Vol. 45, 2000, pp. 103-189.

[8] Ferrasse S., Segal V. M., Hartwig K. T., Goforth R. E. Development of a submicrometergrained microstructure in aluminum 6061 using equal channel angular extrusion, Journal of Materials Research Society Vol. 12, No. 5, 1997, pp. 1253-1261.

[9] Valiev R. Z., Langdon T. G. Achieving exceptional grain refinement through severe plastic deformation: New approaches for improving the processing technology, Metallurgical and Materials Transactions A, Vol. 42, No. 10, 2011, pp. 2942-2951.

[10] Pramono A., Kollo L., Kallip K., Veinthal R. Hot and cold of pressing effect on ECAPparallel channel composite based on Al/ANF material, Advanced Materials Research, Vol. 1123, 2015, pp. 343-347.

[11] Murashkin M. Yu., Bobruk E. V., Kil'mametov A. R., Valiev R. Z. Structure and mechanical properties of aluminum alloy 6061 subjected to equal-channel angular pressing in parallel channels. ISSN 0031-918X, The Physics of Metals and Metallography, Vol. 108, No. 4, 2009, pp. 415-423.

[12] Murashkin M. Yu., Sabirov I., Kazykhanov V. U., Bobruk E. V., Dubravina A. A., Valiev R. Z. Enhanced mechanical properties and electrical conductivity in ultrafine-grained Al alloy processed via ECAP-PC. J Mater Sci, Vol. 48, No. 13, 2013, pp. 4501-4509.

[13] Sokol M., Venglar M. System identification of a composite beam, Pollack Periodica, Vol. 12, No. 3, 2017, pp. 43-54.

[14] Berezin I. M., Petunin A. A., Kryuchkov D. I., Kovacs G. L. Finite-element simulation of the cold stamping process of spherical vessels, Pollack Periodica, Vol. 12, No. 1, 2017, pp. 81-92. 